
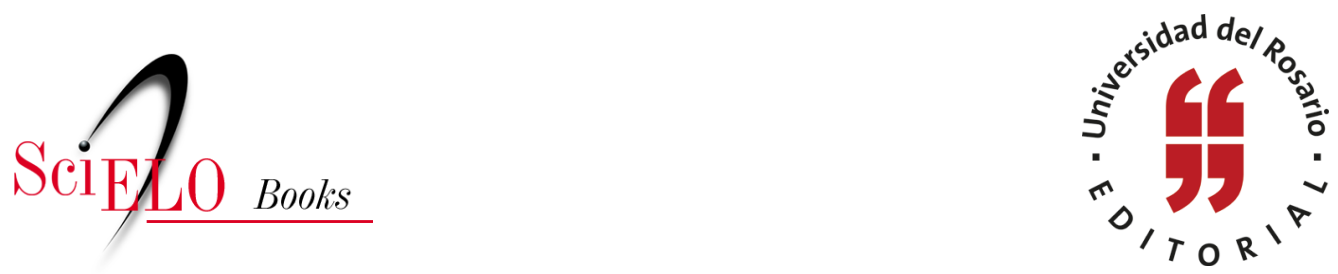

\title{
¿Juntos y bien revueltos? \\ La representación etnocultural de México em estampillas postales de 1930-1940
}

\author{
Henio Hoyo
}

\section{SciELO Books / SciELO Livros / SciELO Libros}

HOYO, H. ¿Juntos y bien revueltos? La representación etnocultural de México em estampillas postales de 1930-1940. In: SCHUSTER, S., ed. La nación expuesta. Cultura visual y procesos de formación de la nación en América Latina [online]. Bogotá: Editorial Universidad del Rosario, 2014, pp. 173-198. Textos de ciencias humanas collection. ISBN: 978-958-738-524-3. https://doi.org/10.7476/9789587385243.0010.

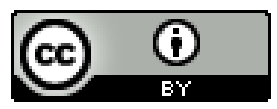

All the contents of this work, except where otherwise noted, is licensed under a Creative Commons Attribution 4.0 International license.

Todo o conteúdo deste trabalho, exceto quando houver ressalva, é publicado sob a licença Creative Commons Atribição 4.0.

Todo el contenido de esta obra, excepto donde se indique lo contrario, está bajo licencia de la licencia Creative Commons Reconocimento 4.0. 


\title{
¿Juntos y bien revueltos? \\ La representación etnocultural de México en estampillas postales de 1930-1940
}

\author{
Henio Hoyo \\ German Institute of Global and Area Studies
}

El objetivo de este capítulo es analizar cómo las estampillas postales se han usado para difundir un imaginario nacional oficial sobre las características étnicas, culturales e históricas de México y los mexicanos. ${ }^{1}$ Para ello, primero se ofrece una introducción general sobre el estudio académico de las estampillas postales, luego se presenta una historia breve sobre los temas e iconografía presentados en estampillas postales de México durante el siglo XIX. Finalmente, me enfoco en el estudio de las estampillas mexicanas emitidas entre 1933 y 1940 — es decir, inmediatamente antes y durante el sexenio del presidente Lázaro Cárdenas del Río (diciembre de 1934-noviembre de 1940) y poniendo atención en los mensajes y representaciones etnoculturales y sus implicaciones ideológicas—. Para ello, se usan catálogos y guías especializados. ${ }^{2}$

1 Por imaginario nacional entiendo una forma específica de imaginario social (véase Taylor 2004) que permite la constitución, la continuación y la legitimidad de una comunidad nacional al establecer tres aspectos esenciales de ella: primero, los requisitos que toda persona, objeto o lugar debe poseer para ser considerado como parte de la nación; segundo, los elementos comunes que se consideran como los fundantes del grupo en términos históricos, sociales e institucionales; tercero, los elementos diferenciadores que, cuando menos en teoría, hacen a dicha comunidad esencialmente diferente del resto de las naciones y grupos en el mundo. Véase Hoyo (2012 y 2014).

2 Mis fuentes serán el listado para México del catálogo universal Scott (Scott Publishing 2007), así como el catálogo especializado de Fernández Terán (1997) y la guía de Ignacio Esteva (1984). Los 


\section{¿Por qué usar estampillas?}

Las estampillas (también llamadas timbres o sellos postales) son inventos relativamente recientes, directamente asociadas con la Revolución Industrial y sus consecuencias sociales: migraciones masivas internas e internacionales, crecimiento urbano, expansión en las comunicaciones e incremento en la alfabetización.

En este sentido, tanto en la Inglaterra del siglo XIX como en muchos otros lados del mundo, el aumento en la demanda por servicios de correo había sobrepasado la capacidad de los servicios de mensajería personal, los cuales además eran extremadamente caros. Además, dado que el importe del mensaje era variable y debía ser cubierto por el destinatario de la carta, una gran cantidad de ellas eran rechazadas ante la imposibilidad de cubrir el costo (véanse al respecto Daunton 1985; Golden 2009; John 1995).

Para resolver esta situación, en 1837 sir Rowland Hill propuso una reforma integral del servicio postal de Inglaterra. Su sistema se basaba en el prepago por el servicio postal, según tasas fijas de acuerdo con el peso de la carta y la distancia que iba a recorrer. Y para hacer posible dicho sistema, Hill planteó la creación de pequeñas estampas que mostrarían el importe que se debía pagar de acuerdo con la tasa fija aplicable. El usuario compraría la estampilla correspondiente y luego la adheriría a la carta, como prueba de pago del servicio postal por todo el trayecto y hasta el domicilio del destinatario indicado en el sobre. Así, la primera estampilla postal de la historia (el Penny Black) fue emitida en 1840 con el busto de la reina Victoria (véanse Daunton 1985; Muir 1990). El sistema fue un éxito y rápidamente fue adoptado en todo el mundo, pues incrementó enormemente la comunicación escrita y trajo profundas implicaciones para la vida de individuos y sociedades (Golden 2009).

Pese a su importancia histórica, las estampillas postales han sido sorprendentemente desdeñadas en la academia (Deans y Dobson 2005; Reid 1984). De hecho, cuando son usadas, casi nunca son como fuente de información, sino simplemente como materiales de apoyo, por ejemplo, como ilustración ocasional en un libro. Al parecer, en la academia - y particularmente en las ciencias sociales- el estudio de las estampillas es considerado una actividad "de coleccionistas" y no de investigadores serios.

Esto es bastante sorprendente, ya que, por un lado, la extraordinaria abundancia de estampillas postales en todo el mundo permitiría un número casi ilimitado

números entre corchetes corresponderán al número Scott de la estampilla específica. Excepto cuando se indique lo contrario, todas las imágenes provienen de la colección privada José Luis Hoyo Pröhuber. 
de estudios y comparaciones; por el otro, objetos muy relacionados como monedas y billetes de banco sí han logrado un estatus como fuentes válidas de información académica, no solo para investigaciones en historia nacional, regional y económica, sino también respecto a arte, sociología, propaganda política, etcétera. ${ }^{3} \mathrm{Al}$ respecto, se ha señalado a Carlos Stoetzer y Donald Reid como los precursores del estudio académico de las estampillas. Otras de las pocas obras comprehensivas al respecto, podemos encontrar el trabajo introductorio de Altman, la lograda obra comparativa de Child, y el muy detallado estudio semiótico de D. Scott (véanse Reid 1984; Stoetzer 1953; Altman 1991; Child 2008; Scott 1995). A estos se añaden varios estudios de caso. ${ }^{4}$

En dicha literatura se puede detectar un acuerdo más o menos explícito respecto a las dos características más importantes que han hecho de las estampillas medios ideales para la propaganda político-ideológica: su carácter oficial, por un lado, y su distribución internacional, por el otro. Lo primero es resultado del monopolio que los Estados-nación han ejercido sobre la emisión de estampillas, lo cual está consagrado no solo por leyes internas, sino también en el derecho e instituciones internacionales. ${ }^{5}$ Lo segundo es una consecuencia natural de su función postal: las estampillas se distribuyen no solo dentro, sino fuera de las fronteras del Estado que las emite - esto a diferencia de los billetes de banco y monedas, que al menos en principio, están hechos para circular dentro de las fronteras del estado emisor- ${ }^{6}$

3 Véanse, por ejemplo, Helleiner (1999), Hymans (2004), Penrose y Cumming (2011), Shanahan (2003), Unwin y Hewitt (2001), Veselkova y Horvath (2011), entre otros muchos.

4 Dos trabajos muy detallados, productos de investigaciones de doctorado, son los de Navarro (2009) sobre los sellos de la España franquista, y de Siebertz (2005) sobre el caso de Irán. Luego, Igor Cusack, Stanley D. Brunn y Paulina Raento han producido una serie de artículos sumamente interesantes al respecto. Véanse Brunn (2001 y 2011), Cusack (2005), Raento (2006), Raento y Brunn (2005 y 2008). También muy importante es el trabajo de Dobson (2005) respecto a los complejos procesos, negociaciones políticas y actores involucrados la emisión de estampillas. Mi investigación también va en este mismo sentido; algunos adelantos de ella están en Hoyo (2010 y 2012). Finalmente, otros autores y obras relevantes son las de Covington y Brunn (2006), Jones (2001), Kevane (2008), McQueen (1988), Nuessel (1992), Osmond (2008), Osmond y Phillips (2011), Pierce (1996), Schwarzenbach (1999) y Wallach (2011).

5 A este respecto véase Codding (1964). Aunque han circulado estampillas emitidas por entidades privadas, estas son excepciones y dependen de la compañía tenga una red de distribución en el país de destino. En cambio, una estampilla postal respaldada por la UPU tiene validez universal: cubre el envío hasta su destino sin importar cuántos países cruce.

6 Respecto al papel de la moneda en el proceso de delimitación (real y conceptual) de la nación véase Helleiner (1997 y 1999). 
Otros especialistas han mencionado más características relevantes de las estampillas. Por ejemplo, su mismo formato y tamaño obligan a que cualquier mensaje en ellas sea sumamente "enfocado", es decir, directo y muy conciso. ${ }^{7}$ Pero, a la vez, las estampillas se pueden producir muy rápidamente y en series que incluyen muchos ejemplares de valores distintos (a fin de cubrir diferentes tarifas postales) y, por ende, cada una puede presentar un diseño particular. En ese sentido, las estampillas son un medio propagandístico sumamente versátil (Hoyo 2012, 21).

Por otro lado, se debe recordar que las estampillas están íntimamente ligadas a la creación y desarrollo del servicio postal: una de las primeras agencias centralizadas del Estado moderno que presta un servicio público directamente a los ciudadanos y cuyas oficinas y representantes llegan hasta los más alejados rincones del territorio nacional (Hoyo 2012, 21). Por ende, para los ciudadanos, las estampillas se convirtieron en representantes de un poder central, nacional, incluso en lugares donde otros impresos y productos oficiales no podían llegar de manera cotidiana (véase Daunton 1985).

Finalmente, las estampillas son objetos de producción y circulación masiva, y ciertamente se pueden incluir dentro de las formas de "nacionalismo banal" a las que se refiere Michael Billig (1995). Sin embargo, también es cierto que en su uso cotidiano, las estampillas toman un carácter mucho más individual, incluso personal. Esto es: un billete de banco o moneda se utiliza cientos de veces por personas anónimas, de manera bastante automática; en cambio, las estampillas están hechas para ser usadas una sola vez. Son fijadas a un envío particular, remitido por una persona con nombre y apellido, que va dirigido a otra igual y, muy posiblemente, que trata temas del ámbito personal, familiar, incluso íntimo. Además (y de nuevo, en contraste con los billetes de banco), las estampillas son frecuentemente dignas de atención: en general, la primera acción del receptor de una carta es leer el nombre del remitente y, luego, observar la estampilla, especialmente si esta tiene un diseño llamativo (Hoyo 2010, 74). ${ }^{8}$

Por todas estas razones, las estampillas han sido vehículos ideales para transmitir mensajes y propaganda oficiales; de hecho, son verdaderas formas de represen-

7 Como Osmond y Phillips (2011, 1138 y 1139) han argumentado recientemente, por su mismo formato, las estampillas obligan al diseñador a telescope in o zoom in en un tema en particular. De hecho, como bien lo advierte Scott $(1995,13)$, las estampillas postales son probablemente el producto cultural de mayor densidad ideológica por centímetro cuadrado.

8 Respecto a los efectos de la expansión del servicio postal en las costumbres sociales y en la vida privada, véase Golden (2009). 
tación masiva de la nación como comunidad imaginada. ${ }^{9}$ No en balde se les ha llamado tanto autorretratos del Estado como representaciones oficiales de la nación. ${ }^{10}$

\section{El bosque o los árboles: narrativas en las estampillas ordinarias vs. conmemorativas}

Aunque existe una gran cantidad de formas para clasificar los tipos de estampillas existentes, hay dos grandes grupos que son fácilmente identificables: primero, las estampillas de tipo permanente u ordinario; segundo, las estampillas conmemorativas.

Las estampillas ordinarias están completamente diseñadas para cubrir la demanda de servicios postales de manera rápida y eficiente. Por ello, son producidas en grandes "series" que incluyen diversos valores, para así poder cubrir todas las posibles tarifas del servicio de correos: desde una tarjeta postal hasta un paquete, tanto para destinos nacionales como para extranjeros. Por ende, cada uno de esos valores dentro de la serie puede, en teoría, tener un diseño distinto al resto. Además, dado su uso intensivo, las series de estampillas permanentes se producen y reimprimen masivamente y durante largos periodos de uso, que se miden en años o incluso décadas, durante los cuales sufren solo pequeñas modificaciones como ajustes en el valor o variaciones de colores.

Para nuestro caso, es muy importante tomar en cuenta que las series permanentes son concebidas, precisamente, como series y no como simples agregados de estampillas diversas. Esto es: las series permanentes casi siempre están ideadas a partir de un tema central (por ejemplo, "trajes típicos del país”, "grandes gestas de nuestra historia" "personajes centrales de nuestra cultura”) y, luego, cada estampilla dentro de dicha serie será diseñada para presentar a un aspecto o ejemplo, cuidadosamente seleccionado, de dicho tema central. ${ }^{11}$

En este sentido, las series permanentes pueden considerarse una micronarrativa oficial y visual sobre un tema. De hecho, es muy común que dicha narración sea explícita (por ejemplo, mediante un texto o título en la estampa) y que además

9 Respecto a las estampillas como piezas visuales de una comunidad imaginada, véanse, por ejemplo, Covington y Brunn (2006) y Leclerc (1994).

Como les llaman Navarro (2009) y Kevane (2008), respectivamente.

11 Existe otro tipo de series permanentes, donde el mismo motivo se repite en cada valor y estampilla, con solo variaciones en cuanto a color o en detalles muy particulares. Un ejemplo clásico son las series que repiten el mismo escudo de armas o retrato del soberano en distintos tonos. Sin embargo, este tipo no es tan interesante para nuestro caso. 
siga un orden fácilmente identificable: por ejemplo, iniciando con el valor más bajo de la serie y culminando con el más alto, de acuerdo con un criterio determinado (cronológico, geográfico, conceptual o cualquier otro).

Precisamente por ello, ciertas estampillas dentro de la serie tienen especial importancia. Las de valor más bajo son las que "abren" la serie y presentan su temática. Además, dado su bajo costo, tienden a ser de uso bastante común en los servicios postales normales y, por ende, su visibilidad pública es elevada. Por su parte, las estampillas de valor más alto tienen las funciones de "cierre" o culminación de la serie, tanto en sentido real como simbólico. Su uso postal efectivo puede ser limitado por su alto costo monetario, por ejemplo, solo en caso de paquetes o servicios internacionales. Sin embargo, estas estampillas también tienden a ser visualmente más atractivas, por lo que su distribución entre los círculos filatélicos tiende a ser mucho mayor. ${ }^{12}$

Finalmente, las series permanentes son diseñadas para usarse durante largos periodos; por ende, se espera que los temas y símbolos usados en ellas no cambien en muchos años. En otras palabras: las estampillas de la serie permanente deben ser relativamente inmunes a las variaciones político-ideológicas que resulten de la llegada de distintas administraciones y partidos al poder. Así, sus temas y diseños tienden a enfocarse en las tradiciones y objetos culturales más aceptados, en los momentos más ampliamente reconocidos como trascendentales para la historia nacional o en los símbolos nacionales más consolidados, de los que no se espera un cambio fundamental en el corto o mediano plazo.

En este sentido, cuando son examinadas desde un punto ideológico, las estampillas de las series permanentes hacen una narración general sobre la nación y sus características y se centran en los elementos ideológicos, representativos y simbólicos más básicos de ella. Tanto es así que una regla casi sin excepciones es que los cambios drásticos en la narrativa político-ideológica de las series permanentes solo sucederán en ocasión de transformaciones políticas muy abruptas, incluso revolucionarias en el Estado-nación que las emite. Esto ha quedado muy claro, por ejemplo, después de los procesos de transición a la democracia. ${ }^{13}$

12 Los valores intermedios de la serie que corresponden a las tarifas postales más comunes son, evidentemente, los que tendrán mayor circulación real entre los usuarios, particularmente aquellas estampillas cuyo valor cubre la tarifa de una carta común a un destino nacional. En consecuencia, las autoridades postales tienden a ponerles una atención especial, sobre todo respecto a qué evento o diseño en particular van a mostrar.

13 Respecto a cómo las estampillas han reflejado cambios políticos abruptos, véanse Brunn (2001 y 2011), así como Child (2008, 57-74). 
En contraste con la visión general de las series ordinarias, y como su nombre lo indica, las series conmemorativas están hechas explícitamente para celebrar un evento o hecho particular. Por ello, son casi siempre emisiones únicas, de venta temporal (de días a meses, rara vez más de un año), y generalmente abarcan un número mucho menor de denominaciones: en muchas ocasiones las "series" conmemorativas se componen de una sola estampilla. Son, de verdad, hechas para la ocasión.

En ese sentido, a las estampillas conmemorativas también se les aplica la regla que rige para toda conmemoración oficial: el objetivo con ellas no es solo recordar o celebrar cierto evento porque sí, sino celebrarlo o recordarlo de una manera particular (véanse al Bucur y Wingfield 2001; Spillman 1997). En comparación con la narrativa general de las series ordinarias, las series conmemorativas están mucho más ligadas a las prioridades e intereses de una administración o gobierno específicos en un momento determinado: ellas indican qué evento, contemporáneo o del pasado, se considera tan importante como para dedicarle una estampilla especial.

En resumen: ciertamente, el estudio de las estampillas postales permite analizar los elementos e implicaciones político-ideológicas de la iconografía que se presenta en ellas. Además, las diferencias en la vigencia temporal y diseño de los distintos tipos de estampillas también permiten un análisis más profundo. Las estampillas de la serie permanente, con su uso de elementos, símbolos y referencias que deberán estar vigentes durante largos periodos y distintos gobiernos, dan una visión general y hacen (por decirlo de alguna manera) una narración longue durée de la nación. En cambio, las series conmemorativas, diseñadas durante gobiernos específicos para celebrar ocasiones y eventos particulares permiten descubrir (y comparar) tanto la forma en que dicho gobierno interpreta el pasado como sus objetivos y prioridades políticas en ese momento.

\section{Presentando a México en estampillas}

La historia del correo mexicano ha sido bastante tortuosa y, a la vez, bastante poco estudiada. ${ }^{14}$ Mas es bien conocido que la primera estampilla mexicana fue emitida en 1856, como parte de una reforma del sistema postal nacional, siguiendo el modelo inglés (figura 1). Esta primera estampilla presentaba un busto del cura y héroe independentista Miguel Hidalgo y Costilla, comúnmente llamado el "Padre de la

14 Su estudio se limita básicamente a las obras de Carrera Stampa (1970), Cárdenas de la Peña (1987) y Gojman (2000). Para una breve sinopsis oficial contemporánea, véase Correos de México (2010). 
Patria”. De hecho, distintos retratos del mismo prócer dominaron las estampillas de México durante casi todo el resto del siglo.

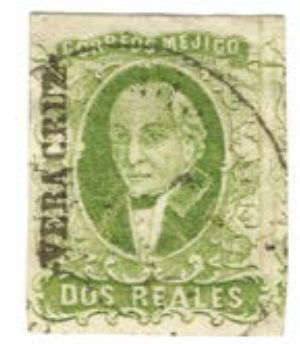

Figura 1. Primera serie de estampillas postales de México [Scott 3]

Durante ese periodo, el correo mexicano tuvo muchas limitaciones y una ineficiencia generalizada. Sin embargo, ello cambió con el régimen de Porfirio Díaz (1876-1880 y 1884-1910). En su largo mandato, el correo pasó a ser considerado una de las instituciones más estratégicas del Estado mexicano y se invirtieron grandes sumas en lograr su modernización administrativa y logística.

\section{La tímida irrupción del tema indígena: siglo XIX}

Como parte de las reformas porfirianas, en 1895 una nueva serie de trece estampillas basadas en cinco diseños distintos vino a cambiar la tradición filatélica mexicana. En vez de honrar a héroes como el perenne Hidalgo, la nueva serie aparentemente se centraba en presentar medios de comunicación y distribución del correo: así, la serie incluía el mensajero a pie, el mensajero a caballo, la diligencia de correo y el ferrocarril. Sin embargo, el diseño faltante (correspondiente a la estampilla de cinco centavos) representaba el monumento a Cuauhtémoc, el último rey azteca. ${ }^{15}$

Como bien lo ha señalado Rebecca Earle, esta fue la primera vez que México hacía referencia a su pasado prehispánico en una estampilla (Earle 2005, 401). ${ }^{16} \mathrm{Y}$

15 Dicho monumento había sido inaugurado unos años antes en el Paseo de la Reforma de la Ciudad de México y desde su misma concepción tomó una importancia simbólica enorme, como parte de la reivindicación del pasado indígena y su integración en el discurso oficial como uno de los pilares del México moderno, lo cual era un objetivo seguido activamente por el régimen de Porfirio Díaz. Véanse Earle (2005 y 2007, 199), Tenorio-Trillo (1996) y Zárate Toscano (2003).

16 De hecho, las intenciones del régimen de Díaz respecto a la remodelación urbana del centro de la ciudad de México, y particularmente el Paseo de la Reforma, eran no solo de índole urbanística, sino 
el hecho de que, temáticamente, la estampilla de Cuauhtémoc tuviera muy poco que ver con el resto de la serie (que representaba formas de transporte del correo) no hace más que subrayar su importancia simbólica (figura 2).

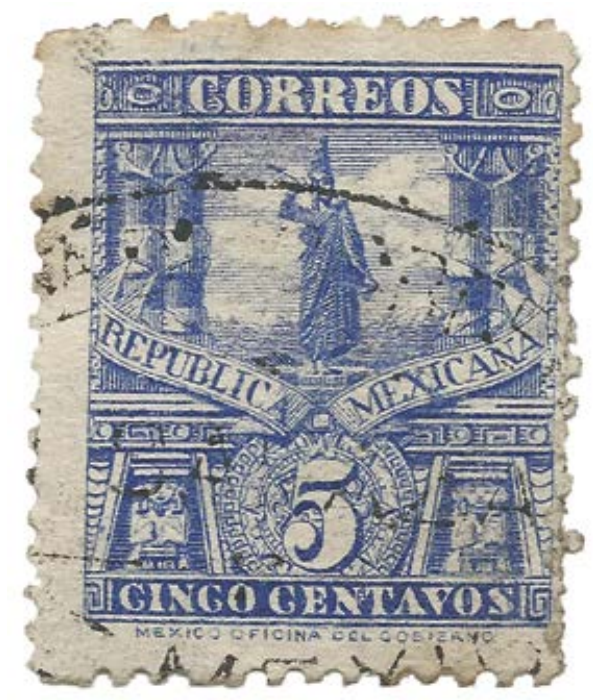

Figura 2. Estatua de Cuauhtémoc, primera representación prehispánica [Scott 247]

Empero, también se debe señalar que antes de 1895 ya habían circulado estampillas que si bien no aludían directamente al pasado prehispánico, sí contenían implicaciones indígenas. El primer caso es tanto controvertido como significativo. En 1864, una estampilla fue emitida presentando el escudo nacional: un águila parada sobre un nopal mientras devoraba una serpiente, lo cual es herencia directa de la mitología azteca sobre la fundación de México-Tenochtitlán. Sin embargo, llama la atención que esta estampilla no fuera emitida por el gobierno republicano de Benito Juárez, sino por su oponente directo: el Segundo Imperio Mexicano de Maximiliano de Habsburgo (Carrera Stampa 1970, 213-217; Esteva 1984, 18; Fernández Terán 1997). ${ }^{17}$

abiertamente ideológica: el objetivo era "convertir el Paseo de la Reforma en un eje artístico-monumental que incluyera la materialización de los que se consideraban los principales sucesos históricos. Pero al mismo tiempo era un eje político en el que lucían los personajes que eran aceptados por el régimen en turno" (Zárate Toscano 2003, 426).

17 Otra serie de estampillas del Imperio presentaba un busto de Maximiliano. 
Desde un punto de vista estricto, ello puede imponer problemas en el momento de considerar dicha estampilla como oficial, además de que por la corta vida del Imperio (1863-1867) no tuvo gran circulación. Para nuestro caso, lo más interesante es que fuera justamente el Imperio el que primero presentara un símbolo prehispánico en la historia filatélica de México. En ese sentido, la estampilla puede leerse como parte de un esfuerzo por legitimar el régimen imperial en raíces históricas profundas, incluso prehispánicas, en contraste con la referencia a Hidalgo, personaje independentista criollo, que había aparecido en todas las estampillas republicanas. Aún más: las estampillas imperiales también fueron las primeras en utilizar la nomenclatura de "México" con "x" (lo cual también tiene una connotación indígena) a diferencia de las republicanas, que aún seguían presentado la forma hispanizada "Méjico" (Esteva 1984, 18).18

Existe un segundo precedente de una estampilla mexicana con implicaciones indígenas, aunque ciertamente no prehispánicas, y ello hecho probablemente con objetivos políticos en mente. En 1879, durante los primeros años del porfiriato, una nueva serie permanente fue emitida con el retrato del presidente Benito Juárez (1808-1872). Es más, esta fue la primera vez que una estampilla republicana presentaba a cualquier persona que no fuera Hidalgo.

Por supuesto, el retrato de Juárez no es una representación prehispánica. Sin embargo, también es cierto que la estampilla presenta de manera bastante fiel los rasgos indígenas del recientemente fallecido expresidente y héroe nacional. Además, hay un dato sumamente interesante y que insinúa una influencia política: mientras que las estampillas con bustos de Hidalgo se siguieron emitiendo y utilizando para la correspondencia interna, las nuevas estampillas de Juárez fueron utilizadas exclusivamente para el correo exterior (figura 3) (Carrera Stampa 1970, 227; Esteva 1984, 40). ${ }^{19}$

\footnotetext{
18 Después del triunfo de Juárez y la ejecución de Maximiliano, en 1867, la nomenclatura con $x$ fue adoptada como oficial por los republicanos (Esteva 1984, 18).

19 Según Fernández Terán $(1997,30)$, las estampillas de Juárez solo fueron autorizadas para correo interno hasta 1883.
} 


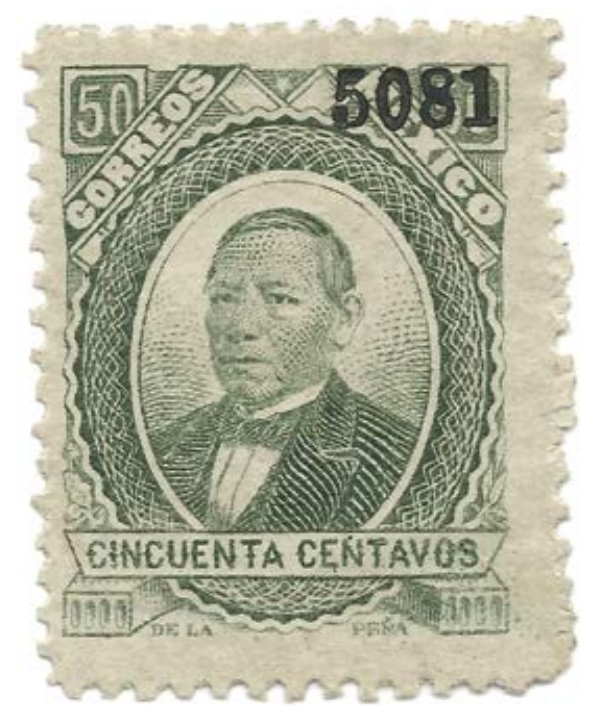

Figura 3. Juárez [Scott 128]

Filatélica y administrativamente hablando, no hay razones claras de por qué una nueva serie, y en particular una nueva persona, debía de presentarse justo en ese momento y solo para estampillas de ese tipo. Probablemente, la explicación de esto reside en el mensaje implícito. Esto es: parece difícil pasar por alto el hecho de que la persona elegida para representar a México en el exterior no fuera otro que el presidente (indígena) que guió la resistencia contra las fuerzas de Napoleón III; terminó por derrotar al Segundo Imperio y sus aliados europeos y encima, ordenó el fusilamiento de Maximiliano de Habsburgo, en fecha tan reciente como 1867 (Hoyo 2012, 23). ${ }^{20}$ Entonces, poner a Juárez, y resaltar su condición nativa, era una manera de afirmar la independencia del país en el exterior - justo adonde se destinaba la estampilla-. Si efectivamente ese era el mensaje, ciertamente era uno muy a la Díaz. ${ }^{21}$

20 Se puede argumentar que la nueva serie de Juárez fue hecha para facilitar el procesamiento de la correspondencia, al diferenciar clara y rápidamente el correo dirigido al exterior con el interno. Sin embargo, eso tampoco justifica en sí la inclusión de un nuevo personaje: en todo caso, un rediseño de las estampillas existentes, o incluso un simple cambio de color en ellas, hubiera bastado.

21 Como dato adicional, Porfirio Díaz fue uno de los más connotados militares al servicio de Juárez, precisamente, durante la intervención francesa y en la lucha contra el Segundo Imperio. 
En los años siguientes los temas indígenas no desaparecieron, aunque tampoco fueron preponderantes. Finalmente, es bastante llamativo cómo la emblemática serie del centenario de 1910, emitida para conmemorar del primer centenario de la Independencia, mostró referentes y temas exclusivamente criollos: ni siquiera los líderes mestizos más importantes (como Morelos o Guerrero) merecieron ser homenajeados, por no hablar de los indígenas aunque fuera simplemente como grupo social (véase Hoyo 2012, 25 y 26). En ese sentido, las alusiones al mundo indígena en estampillas se habían limitado a monumentos y símbolos de un pasado glorioso, y a Juárez como un caso destacado; pero no a los indígenas en tanto conjunto y mucho menos a los que efectivamente vivían en el México de la época.

\section{Y la Revolución les hace justicia... aunque sea filatélica}

La Revolución de 1910 tuvo, por supuesto, graves repercusiones en el correo mexicano. De hecho, la emisión de estampillas solo se regularizó hasta la década de los veinte. Desde ese año y hasta los años treinta, las referencias indígenas siguieron presentes aunque no preponderantes: por ejemplo, las nuevas series repetían el consabido monumento a Cuauhtémoc o el escudo nacional, con sus connotaciones aztecas. La única novedad, ciertamente importante, fue una estampilla de la serie permanente de 1921 que presentaba la Pirámide del Sol en Teotihuacán: esto es, el primer objeto genuinamente indígena y prehispánico. ${ }^{22}$ Aun así, la representación del pasado indígena seguía siendo bastante limitada; se preferían los ejemplos de arquitectura urbana y hasta referencias abiertamente coloniales, como la estatua a Cristóbal Colón.

Sin embargo, los años 1933-1934 marcaron un cambio radical en las representaciones étnicas en estampillas mexicanas. La primera señal de ello fue en marzo de 1933, cuando se emitió una estampilla que reproducía una pintura muy conocida hecha por Félix Parra en 1875, que presentaba a fray Bartolomé de las Casas en su histórico papel de defensor de los indígenas..$^{23}$ Esta estampilla es de pequeño tamaño

22 Hasta entonces, las estampillas con motivos indígenas en realidad habían presentado obras modernas que interpretaban el pasado: un monumento de manufactura moderna, un escudo de armas. En cambio, la Pirámide del Sol es un objeto directamente producido por las civilizaciones indígenas. El cambio discursivo no es menor: de aludir a un pasado indígena idealizado, se pasa a presentar pruebas tangibles de él.

23 La pintura original se conserva en el Museo Nacional de Arte de la ciudad de México, pero también puede apreciarse en internet. Véase Google Art Project (2012). 
y su calidad de impresión no es la mejor; sin embargo, era una pieza sobresaliente en otros sentidos (figura 4).

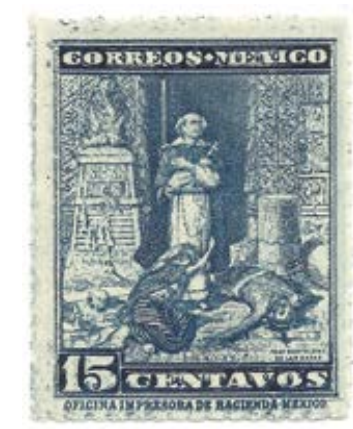

Figura 4. Fray Bartolomé de las Casas, protector de los indígenas [Scott 683]

Por un lado, esta fue la primera vez que se presentaba a los indígenas como grupo bumano específico. Antes solo habían sido representados indirectamente, por ejemplo, mediante sus obras o por símbolos y objetos relacionados con ellos, o a lo sumo gracias a individuos connotados que pertenecían a dicho grupo (Juárez). ${ }^{24}$ Jamás en la filatelia ellos habían merecido una alusión como colectividad real. Segundo y más importante, nunca hasta 1933 se había aludido en una estampilla a la situación social e histórica que habían enfrentado los pueblos indígenas de México.

En ese sentido, la estampilla de 1933 ya era sumamente innovadora en términos de sus implicaciones político-ideológicas. Sin embargo, la verdadera revolución en las representaciones etnoculturales de los mexicanos sucede en 1934, cuando dos series permanentes y dos conmemorativas fueron emitidas (en cada caso, una para servicios terrestres y otra para aéreos) y cuyas implicaciones en términos de la imagen etnocultural que se buscaba proyectar de México eran de muy largo alcance.

\section{Así me los imagino: las series conmemorativas pro-UNAM}

Oficialmente, las series pro-UNAM de 1934 tenían dos objetivos: por un lado, celebrar la toma de posesión de Lázaro Cárdenas del Río como presidente para el periodo 1934-1940; por el otro, recaudar fondos a favor de la Universidad Nacional

24 Hay que señalar que los retratos de Juárez habían perdido progresivamente el acento indígena, al grado que su aspecto en una serie emitida en 1926 era ya prácticamente el de un caucásico. Véase Scott Publishing $(2007,666)$. 
Autónoma de México (UnAM) (Esteva 1984, 94-97; Fernández Terán 1997, 156157). Claramente, se dirigían principalmente al público coleccionista y, de hecho, solo fueron emitidas durante un mes (septiembre de 1934) (Esteva 1984, 94). Pese a su limitada distribución, fueron objeto de mucha atención no únicamente por su alta calidad artística, sino por su significado simbólico, lo cual es evidente en el caso de la serie para servicios terrestres (figura 5).
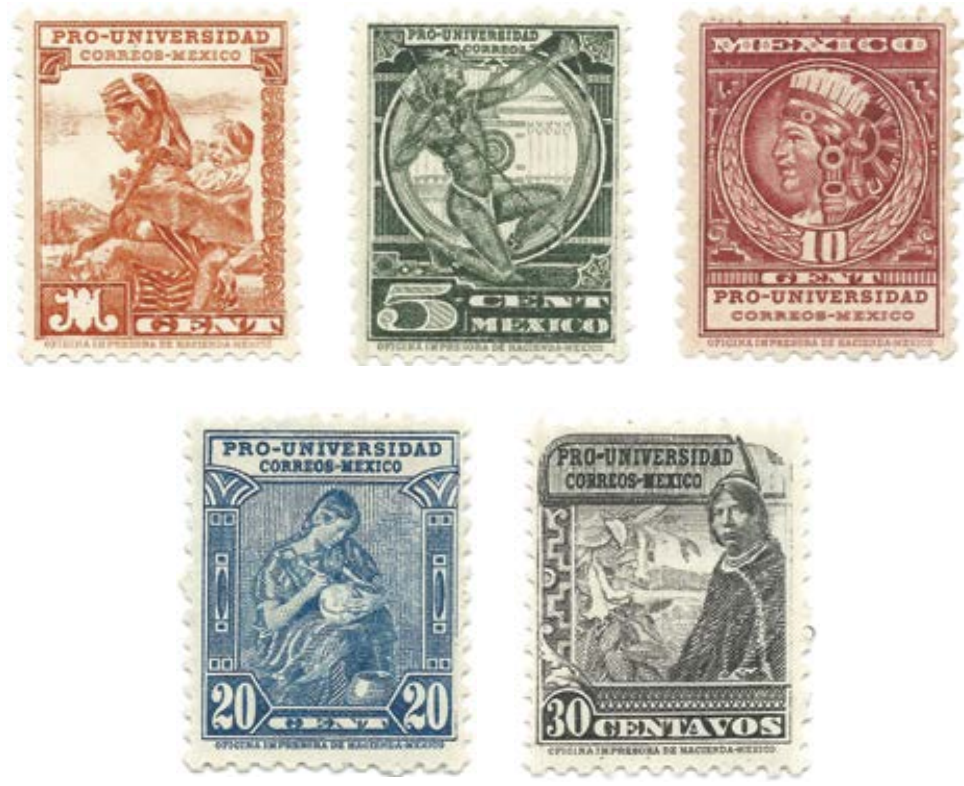

Figura 5. Serie pro-UNAM para correo terrestre (selección) [Scott RA13B, 698, 699, 700, 701]

Esta serie presenta algunas variaciones de estilo, resultado de la intervención de varios diseñadores y artistas, mas en su conjunto está dedicada de manera exclusiva al mundo indígena. Hay una clara preferencia por los motivos aztecas, aunque el "peón" (empleado agrícola) retratado en la estampilla de treinta centavos [Scott 701] podría también pertenecer a otro grupo (Scott Publishing 2007, [701]).25 Los personajes son representados con rasgos fuertes y llamativos (y, ciertamente, con una buena dosis de idealización) y, sobre todo, como personas activas y crea-

25 Además, la estampilla de veinte centavos puede ser bastante equívoca: aunque supuestamente representa a una “indígena alfarera”, el retrato podría corresponder más bien al de una vestal griega. Véanse Fernández Terán (1997, 156 [1110]) y Scott Publishing (2007, [700]). 
doras: muy lejos de la inmovilidad de piedra del monumento a Cuauhtémoc o de los retratos juaristas.

El valor más bajo de la serie es de un centavo, y muestra a una mujer cargando a su niño de la forma tradicional. ${ }^{26}$ En cambio, los valores más altos se refieren a dos hombres, probablemente sacerdotes, ofreciendo sacrificios en un altar. Con la salvedad de los valores de cinco y diez centavos, parece haber una cierta narrativa que va desde las actividades cotidianas (el cuidado de la familia, la decoración de vasijas o la agricultura) pasa luego a las artes refinadas (labrado en piedra y pintura) y finaliza con las actividades sagradas. Así, la serie parece presentar una serie de flashes de una comunidad prehispánica imaginada (Anderson 1991; Covington y Brunn 2006). Y, ciertamente, bastante idealizada.

Por su parte, la serie pro-UNAM para servicios aéreos comprendía ocho estampillas y temáticamente se enfocó en presentar distintos paisajes emblemáticos de México, cada uno sobrevolado por un avión. Solo dos de las ocho estampillas incluyeron alguna referencia indígena; sin embargo, ambas son notables. La de treinta centavos, que es la segunda de la serie, presenta las pirámides del sol y de la luna en Teotihuacán (figura 6).

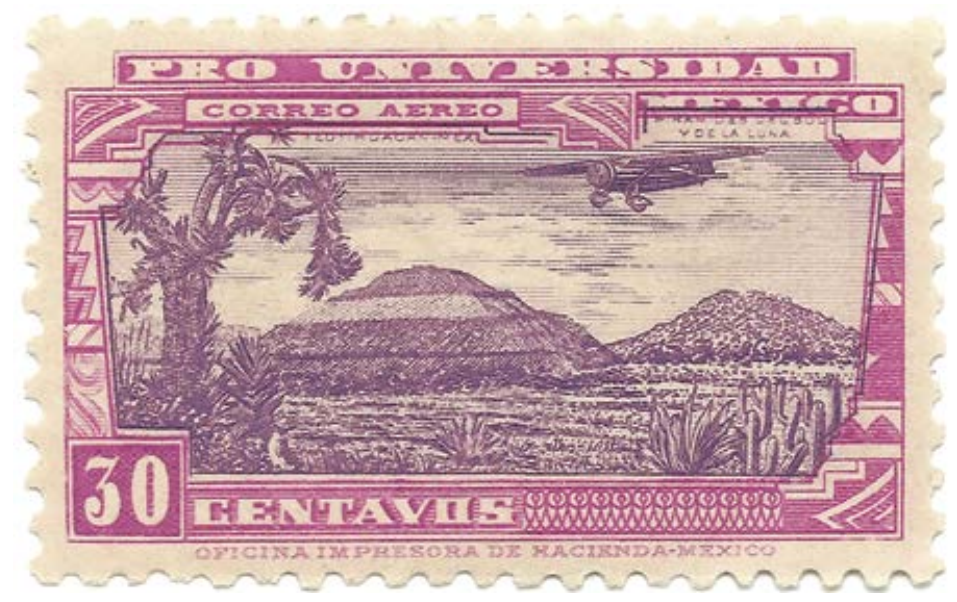

Figura 6. Serie pro-UNAM para correo aéreo: pirámides [Scott C55]

26 Este valor es considerado en el catálogo de Scott dentro de una categoría especial, por lo que no es listado con el resto de la serie [número asignado: RA13B]. Sin embargo, el catálogo especializado de Fernández Terán (1997), así como la guía de Esteva (1984), la consideran parte de una misma serie, ya que fue emitida al mismo tiempo y tanto su formato como su temática son similares. 
Por su parte, la de mayor valor (veinte pesos: una pequeña fortuna para la época) presenta una espectacular reproducción de una indígena, posiblemente mixteca, ${ }^{27}$ parada frente al calendario azteca y al lado de un paisaje de la ciudad de México y el correspondiente avión en los cielos (figura 7).

Esta estampilla es considerada por algunos especialistas una de las más estéticamente logradas en la historia filatélica de México (Esteva 1984, 96)..28 Además de su valor artístico, ideológicamente esta estampilla tiene implicaciones bastante profundas: conjunta el objeto prehispánico más reconocido (el calendario azteca) con símbolos de la modernidad (el avión y la ciudad de México), así como un ideal de mujer indígena. Lo que es más interesante, la composición pareciera indicar que dicha indígena es parte real del presente, y no solo recuerdo o imagen de un pasado glorioso, pero lejano. En ese sentido, esta estampilla es la primera sugerencia de que los grupos indígenas; de hecho, también son parte del México actual. Que ello suceda hasta 1934 no deja de ser impresionante (figura 7).

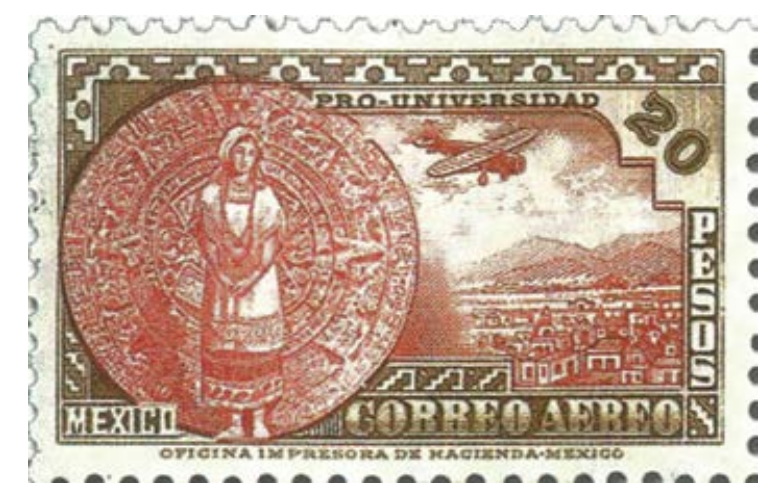

Figura 7. Serie pro-UNAM para correo aéreo: indígena y calendario azteca [Scott C61]

Fuente: Boletín AMEXFIL 27, n. ${ }^{\circ} 148$ (ene-jun 2014), 1.

Como hemos visto, estas series fueron conmemorativas, de distribución bastante limitada y para celebrar ocasiones muy específicas. Al comparar sus imágenes y significados con otras estampillas emitidas en el periodo, podemos comprobar qué tanto eran representativas de un esfuerzo oficial por promover una cierta idea de México, en términos etnoculturales.

\footnotetext{
27 Asílo considera Esteva $(1984,96)$. Por su parte, Fernández Terán la clasifica como maya $(1997,157)$.

En realidad, el grado de detalle no es suficiente para descartar ninguna de estas opciones.

De hecho, su valor en la actualidad rebasa los mil dólares.
} 


\section{De yalatecas a charros: la serie ordinaria terrestre de 1934}

La “emisión regular" de 1934 vino a sustituir otra que estaba en servicio desde 1921, y cuyos principales temas eran monumentos y piezas arquitectónicas. La nueva emisión regular de 1934 no solo fue emitida desde poco antes y durante todo el régimen de Lázaro Cárdenas, sino que su uso se extendió por dos administraciones más: la de Manuel Ávila Camacho (1940-1946) y por más de la mitad de la de Miguel Alemán (1946-1952), y durante ese periodo solo sufrió pequeñas modificaciones, algunas adiciones, así como ajustes en su valor (Esteva 1984, 96; Fernández Terán 1997, [1126-1140]; Scott Publishing 2007, [707-720]).

Ciertamente, esta "emisión regular" era de bastante menor calidad filatélica y artística cuando se comparaba con las emisiones pro-UnAM. Sin embargo, su valor ideológico era cuando menos el mismo, sino es que mayor, tanto en términos de sus implicaciones como respecto a su visibilidad: a fin de cuentas, estas fueron las estampillas que todos los usuarios del servicio postal mexicano utilizaron durante dieciséis años. La serie completa comprendía doce estampillas, cada una con un diseño distinto y con valores que iban desde un centavo hasta cinco pesos.

Vista en conjunto, resulta muy evidente el objetivo de promover ciertas características étnicas y culturales como las “propias y auténticas" de México. Así, dentro de esta serie se pueden encontrar tres estereotipos de grupos sociales mexicanos (dos de ellos indígenas), así como representaciones de tres objetos/edificaciones prehispánicos; además, otras representaciones —incluidos monumentos de distintas épocas, así como el escudo nacional-completan un mosaico etnocultural muy variado (figura 8 ).

Como ya se dijo, los valores más altos y más bajos de la serie son de especial interés en cuanto a la narrativa y sus implicaciones ideológicas. Es muy llamativo cómo los dos primeros valores (uno y dos centavos) representan a mujeres indígenas: la primera es una "indígena yalalteca" que carga agua de un pozo, presumiblemente a la casa que está justo detrás de ella. La segunda es una "indígena tehuana” que carga un cesto, probablemente de frutas, también frente a una casa (Fernández Terán 1997, 158-159 [1126-1127]; Esteva 1984, 98-99; Scott Publishing 2007, [707-708]). Ambas estampillas son los ejemplos más claros de representar a un grupo indígena determinado mediante un estereotipo etnocultural: no tanto por su aspecto físico (el cual resulta difícil de determinar, debido al tipo de impresión), sino en cuanto a su vestimenta típica, y su forma de vida, incluidos objetos, casas y naturaleza circundante. Y aunque la temporalidad no es explícita, el tipo de edificaciones y vestimenta indican que no se trata de un ambiente prehispánico. 

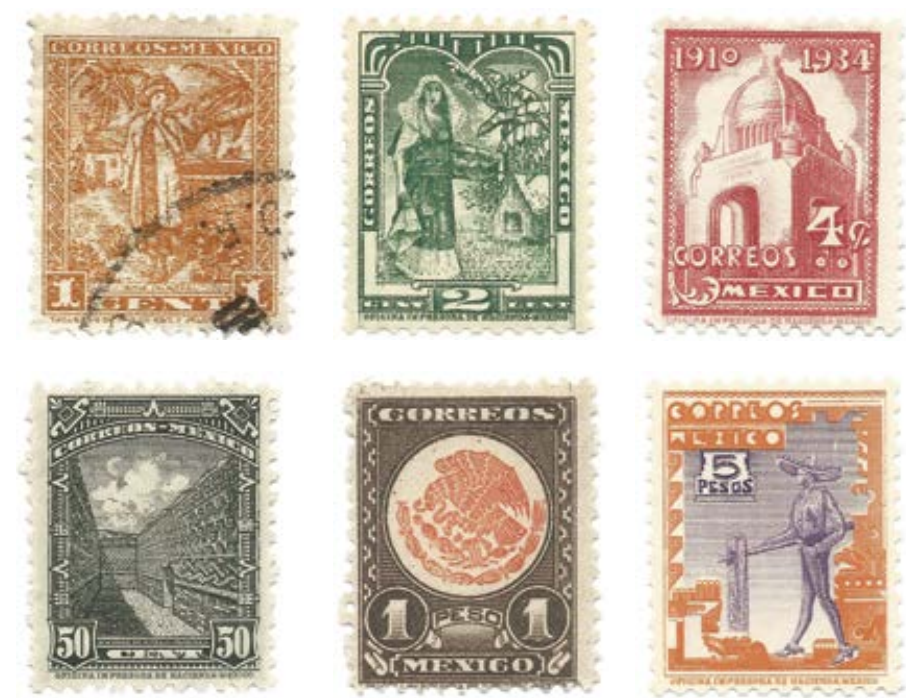

Figura 8. La serie ordinaria de 1934: de indígenas a charros (selección) [Scott 707-709, 718-720]

Los valores intermedios también incluyen varias referencias, pero estas no son solo indígenas, sino también específicamente prehispánicas: dos importantes piezas arqueológicas y las ruinas de una ciudad (Mitla). Luego, varias estampillas adicionales representan piezas arquitectónicas y monumentos que, a su vez, se refieren a distintos momentos de la vida independiente de México.

Sin embargo, lo más interesante es la forma en que culmina la serie. El escudo nacional no ocupa el valor más alto, como podría esperarse, sino el penúltimo. En cambio, la estampilla con el valor más alto (cinco pesos) vuelve a presentar un estereotipo etnocultural; mas esta vez no se trata de un indígena, sino un carácter intrínsecamente ligado al México mestizo y, en particular, a la cultura popular promovida en el régimen posrevolucionario: el charro, ${ }^{29} \mathrm{el}$ cual además está dentro de un marco y ornamentación de origen claramente indígena. Así, este es el primer caso explícito de sincretismo cultural en una estampilla mexicana: hasta entonces, todas las estampillas habían presentado grupos o referencias etnoculturales por separado. En suma, además de las representaciones indígenas en esta y otras series,

29 Respecto a la génesis del charro como figura central del nacionalismo cultural mexicano, véanse Palomar (2004) y Pérez Montfort (2000). Para una visión más general del desarrollo de las artes y su relación con el nacionalismo revolucionario mexicano durante este periodo, véanse Tenorio-Trillo (1996), vv. AA. (1986) y Vaughan y Lewis (2006). 
1934 es también la primera ocasión en que se emite una estampilla que representa un México mestizo. ${ }^{30}$

Por su parte, la serie ordinaria emitida en 1934 para servicios aéreos también incluyó motivos indígenas, la mayoría representaciones de ornamentos, esculturas o pinturas. La serie de nueve estampillas inicia con una alegoría del vuelo, inspirada en motivos prehispánicos y sigue con una escultura monumental del dios Tláloc. Luego, entre los valores intermedios de la serie encontramos una estampilla, sumamente común, con el dibujo de un "caballero águila” (guerrero azteca) que observa el volcán Popocatépetl, junto con otros símbolos vinculados con México como el águila y el nopal.

Pero es la estampilla de mayor valor [Scott C73, Fdez. Terán 1158] la que merece particular atención desde el punto de vista ideológico. En ella se presenta a dos indígenas, probablemente madre e hija, observando el vuelo de un avión. $\mathrm{Si}$ hacemos memoria, el resto de representaciones indígenas se refieren al pasado precolombino o, bien, son de temporalidad ambigua: los indígenas pueden ser habitantes de cualquier época. En cambio, esta estampilla, junto con la de veinte pesos de la serie aérea pro-UNAM, es la primera que presenta de manera explícita a los grupos indígenas constituyendo parte del México contemporáneo. Y probablemente no es una casualidad que ambas correspondan a los valores más altos de sus respectivas series (figura 9). Sin embargo, no puede dejarse de notar el título de la estampilla, escrito en pequeñas letras sobre sus cabezas: "admiración indígena”. Dicho de otra manera, los indígenas están presentes, pero como un atraso que se maravilla frente a la modernidad.

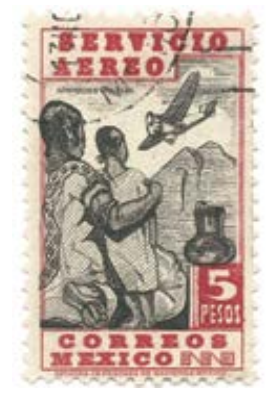

Figura 9. La fascinación ante la modernidad [Scott C73]

30 Respecto al mestizaje como ideología, consúltese el extraordinario estudio de Basave (2002), así como la obra clásica de José Vasconcelos (1997). 


\section{Epílogo: las otras conmemoraciones}

Pese a la irrupción del tema indígena en estampillas postales entre 1933 y 1934, es significativo ver cómo, según el régimen de Lázaro Cárdenas avanzaba, los temas de las estampillas (particularmente las conmemorativas) pasaron de representaciones indígenas, a referencias a la Revolución Mexicana y a sus logros, sobre todo en lo agrario; así como a las obras públicas modernas, las actividades industriales y a la educación.

En buena medida, esta modificación en los temas de las estampillas conmemorativas se debe, por una parte, a las prioridades y políticas específicas del régimen cardenista y, por la otra, al hecho de que en esta época se cumplen varios aniversarios de hechos relacionados a la revolución, como los veinticinco años de la promulgación de los Planes de San Luis, de Ayala y de Guadalupe (lanzados por Emiliano Zapata, Francisco I. Madero y Venustiano Carranza, respectivamente) que fueron parte esencial del proceso de la Revolución Mexicana. Sin embargo, es interesante notar que cuando se hacen representaciones o estereotipos de grupos sociales de México, estos corresponden más bien a mestizos (tanto campesinos como urbanos) o simplemente a "revolucionarios", que a personas con rasgos o de cultura indígena. Particularmente significativa es la última estampilla emitida durante el gobierno de Cárdenas: la famosa "hombre al timón", que indica la fecha del cambio de titular de la Presidencia ( $1^{\circ}$ de diciembre de 1940) y deja así, bien en claro, que una nueva persona está tomando el control de la nave nacional. Sin embargo, también parece que esa persona no tiene mucha huella de ser indígena, o siquiera mestizo; de hecho, parece corresponder más a los cánones y modelos artísticos vigentes en Europa, que a algún tipo étnico en México (figura 10). De esta

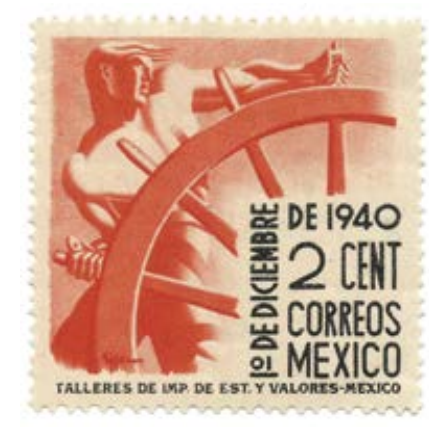

Figura 10. $1^{\circ}$ de diciembre de 1940: un nuevo capitán [Scott 764] 
manera, las estampillas mexicanas después de 1934 y hasta 1940, particularmente las conmemorativas pasaron de celebrar lo indígena, a enfatizar lo revolucionario y “moderno” de México en general, de nuevo, siguiendo la ideología y las políticas corte socialista, activamente promovidas durante el sexenio de Lázaro Cárdenas.

\section{Conclusiones}

Las estampillas emitidas durante los años 1933 y 1934 son enormemente significativas y marcan una completa ruptura con el pasado, en términos de discurso visual e ideológico. Por un lado, hasta entonces los indígenas mexicanos habían estado representados solo de manera simbólica o mediante objetos: la estatua a Cuauhtémoc, la Pirámide del Sol, el águila sobre el nopal... Y aunque, de cierta manera, Juárez era indígena y había sido representado en estampillas, también él había acabado por recibir el mismo trato que Cuauhtémoc: más como el héroe de una gesta pasada, que como un referente de la actualidad del país. Hasta entonces, nunca las estampillas mexicanas habían presentado a los indígenas como grupo social activo y creativo y, mucho menos, como parte del México contemporáneo. Por otro lado, las estampillas mexicanas no habían presentado una narrativa tan clara respecto al mestizaje étnico y cultural como la culminación de un proceso.

Las estampillas de 1933-1934 hicieron eso precisamente. En primer lugar, se presentó a "los" indígenas mexicanos en cuanto a sus características étnico-raciales y culturales, aunque ello fue hecho de manera bastante idealizada y estereotipada. En segundo, se les presentó ya no solo a través de estatuas o pirámides, sino como individuos y actores reales, vinculados a situaciones sociales (por ejemplo, discriminación y persecución, en el caso de la estampilla de Las Casas) y también a actividades creativas y productivas, como demuestra toda la serie pro-UNAM para correo terrestre. Y lo que es tal vez más importante, las estampillas de 1934 se atrevieron a sacar a los indígenas del pasado para colocarlos como parte explícita del presente de México, aunque fuera solo para contemplar la modernidad — la que, al fin y al cabo, conduce al mestizaje- - Esto es particularmente claro para las series ordinarias de 1934, tanto aquella para servicios terrestres (con su narrativa que inicia con mujeres indígenas y culmina con un charro) como aquella para servicios aéreos, con madre e hija indígenas observando, maravilladas, el paso de un avión.

Ambas series ordinarias, como se dijo, continuaron en servicio a lo largo de todo el cardenismo, y aún después. Sin embargo, las estampillas conmemorativas emitidas durante ese mismo periodo evidencian una narrativa distinta, donde el énfasis en lo indígena da paso a temas propiamente revolucionarios e incluso, a 
personificaciones del poder estatal — como lo demuestra "el hombre al timón" (figura 10). En este sentido, las estampillas mexicanas no hacían más que reflejar, de manera muy fiel, la ideología del nacionalismo revolucionario y su búsqueda por establecer bases etnoculturales comunes y oficiales dentro de la compleja sociedad mexicana y, a la vez, la búsqueda de promover las preferencias y prioridades políticas específicas de un gobernante en turno.

\section{Bibliografía}

Altman, Dennis. 1991. Paper Ambassadors: The Politics of Stamps. North Ryde: Angus \& Robertson.

Anderson, Benedict. 1991. Imagined Communities: Reflections on the Origin and Spread of Nationalism. Edición revisada y extendida. London \& New York: Verso.

Basave, Agustín. 2002. México mestizo: análisis del nacionalismo mexicano en torno a la mestizofilia de Andrés Molina Enríquez. México: Fondo de Cultura Económica.

Billig, Michael. 1995. Banal Nationalism. London \& Thousand Oaks: Sage. Boletín AMEXFIL 27, n. 148 (enero-junio de 2014).

Brunn, Stanley D. 2001. "Stamps as Iconography: Celebrating the Independence of New European and Central Asian States". GeoJournal 52, n. ${ }^{\circ} 4: 315-323$.

Brunn, Stanley D. 2011. "Stamps as Messengers of Political Transition”. Geographical Review 101, n. ${ }^{\circ} 1: 19-36$.

Bucur, Maria y Nancy M. Wingfield. 2001. Staging the Past: The Politics of Commemoration in Habsburg Central Europe, 1848 to the Present. West Lafayette: Purdue University Press.

Cárdenas de la Peña, Enrique. 1987. Historia de las comunicaciones y los transportes en México: el correo. Mexico: SCT.

Carrera Stampa, Manuel. 1970. La historia del correo en México. Mexico: SCT.

Child, Jack. 2008. Miniature Messages: The Semiotics and Politics of Latin American Postage Stamps. Durham: Duke University Press.

Codding, George A. 1964. The Universal Postal Union: Coordinator of the International Mails. [New York]: New York University Press.

Correos de México. 2010. “Historia del Correo en México". http://www.correosdemexico.gob.mx/Historia/Paginas/HistoriaCorreoeMexico.aspx 
Covington, Kate y Stanley Brunn. 2006. “Celebrating a Nation’s Heritage on Music Stamps: Constructing an International Community". GeoJournal 65, n. ${ }^{\circ}$ : 125-135.

Cusack, Igor. 2005. "Tiny Transmitters of Nationalist and Colonial Ideology: The

Postage Stamps of Portugal and its Empire”. Nations and Nationalism 11, n. ${ }^{\circ}$ 4: 591-612.

Daunton, M. J. 1985. Royal Mail: The Post Office Since 1840. London \& Dover: Athlone Press.

Deans, Phil y Hugo Dobson. 2005. "Introduction: East Asian Postage Stamps as SocioPolitical Artefacts". East Asia 22, n. ${ }^{\circ}$ 2: 3-7.

Dobson, Hugo. 2005. “The Stamp of Approval: Decision-Making Processes and Policies in Japan and the UK". East Asia 22, n. ${ }^{\circ}$ 2: 56-76.

Earle, Rebecca. 2005. "Sobre héroes y tumbas: National Symbols in NineteenthCentury Spanish America". The Hispanic American Historical Review 85, n. ${ }^{\circ}$ 3: 375-416.

Earle, Rebecca. 2007. The Return of the Native: Indians and Myth-making in Spanish America, 1810-1930. Durham: Duke University Press.

Esteva, Ignacio. 1984. Sellos de Correos de México. Mexico: Promexa.

Fernández Terán, Carlos. 1997. Catálogo de Estampillas Postales de México, 1856-1996. Mexico: SHCP.

Gojman, Alicia. 2000. Historia del correo en México. Mexico: Porrúa-Sepomex.

Golden, Catherine. 2009. Posting It: The Victorian Revolution in Letter Writing. Gainesville: University Press of Florida.

Google Art Project. 2012. “Fray Bartolomé de las Casas, por Félix Parra, 1875”. http:// www.googleartproject.com/collection/museo-nacional-de-arte/artwork/ fray-bartolome-de-las-casas-felix-parra/593091/files/58/593091.html

Helleiner, Eric. 1997. “One Nation, One Money: Territorial Currencies and the Nation-State”. En ARENA WP 17/1997. Oslo: Centre for European Studies, University of Oslo.

Helleiner, Eric. 1999. "Historicizing Territorial Currencies: Monetary Space and the Nation-state in North America”. Political Geography 18, n. $3:$ 309-339.

Hoyo, Henio. 2010. "Posting Nationalism: Postage Stamps as Carriers of Nationalist Messages". En Beyond Imagined Uniqueness: Nationalisms in Contemporary Perspectives, editado por William Glass y Joan Burbick, 67-92. Cambridge: Cambridge Scholars. 
Hoyo, Henio. 2012. "Fresh Views on the Old Past: The Postage Stamps of the Mexican Bicentennial". Studies in Ethnicity and Nationalism 12, n. ${ }^{\circ}$ 1: 19-44.

Hoyo, Henio. 2014. "Post-nationalism: Postage Stamps as Carriers of Nationalist Messages”. Tesis de doctorado, Instituto Universitario Europeo de Florencia. Hymans, Jacques E. C. 2004. “The Changing Color of Money: European Currency Iconography and Collective Identity". European Journal of International Relations $10,{ }^{\circ}$ 1: 5-31.

John, Richard R. 1995. Spreading the News: The American Postal System from Franklin to Morse. Cambridge: Harvard University Press.

Jones, Robert A. 2001. "Heroes of the Nation? The Celebration of Scientists on the Postage Stamps of Great Britain, France and West Germany".Journal of Contemporary History 36, n. ${ }^{\circ}$ 3: 403-422.

Kevane, Michael. 2008. "Official Representations of the Nation: Comparing the Postage Stamps of Sudan and Burkina Faso”. African Studies Quarterly 10, n. ${ }^{\circ}$ 1:71-94.

Leclerc, Jacques. 1994. “The Political Iconology of the Indonesian Postage Stamp. 1950-1970)". Indonesia 57: 15-48.

Mcqueen, Humphry. 1988. “The Australian Stamp: Image, Design and Ideology”. Arena 84 (Spring): 78-96.

Muir, Douglas N. 1990. Postal Reform and the Penny Black: ANew Appreciation. London: National Postal Museum.

Navarro, Guillermo. 2009. "Autorretratos del Estado: una aproximación al sello postal del franquismo como medio de emisión de mensajes ideológicos. 19361975)”. Tesis de doctorado. Ciudad Real: Universidad de Castilla-La Mancha.

Nuessel, Frank. 1992. “Territorial and Boundary Disputes Depicted on Postage Stamps". Studies in Latin American Popular Culture 11: 123-141.

Osmond, Gary. 2008. “'Modest Monuments'? Postage Stamps, Duke Kahanamoku and Hierarchies of Social Memory”. Journal of Pacific History 43, n. ${ }^{\circ}$ 3: 313-329.

Osmond, Gary y Murray G. Phillips. 2011. "Enveloping the Past: Sport Stamps, Visuality and Museums". International Journal of the History of Sport 28, n. ${ }^{\circ}$ 8/9: 1138-1155.

Palomar, Cristina. 2004. "El papel de la charrería como fenómeno cultural en la construcción del Occidente de México”. Revista Europea de Estudios Latinoamericanos y del Caribe 76: 83-98.

Penrose, Jan y Craig Cumming. 2011. "Money Talks: Banknote Iconography and Symbolic Constructions of Scotland". Nations and Nationalism, 17, n. ${ }^{\circ}$ 4: 821-842. 
Pérez Montfort, Ricardo. 2000. Avatares del nacionalismo cultural. Mexico: CIDHEMCIESAS.

Pierce, Todd. 1996. "Philatelic Propaganda: Stamps in Territorial Disputes". Boundary \& Security Bulletin 4, n. 2: 62-64.

Raento, Pauliina. 2006. “Communicating Geopolitics Through Postage Stamps: The Case of Finland”. Geopolitics 11, n. ${ }^{\text {4 }}$ : 601-629.

Raento, Pauliina y Stanley D. Brunn. 2005. “Visualizing Finland: Postage Stamps as Political Messengers". Geografiska Annaler Series B: Human Geography 87, n. ${ }^{\circ}$ 2: 145-164.

Raento, Pauliina y Stanley D. Brunn. 2008. "Picturing a Nation: Finland on Postage Stamps, 1917-2000”. National Identities 10, n. ${ }^{\circ}$ 1: 49-75.

Reid, Donald M. 1984. “The Symbolism of Postage Stamps: A Source for the Historian”. Journal of Contemporary History 19, n. ${ }^{\circ}$ 2: 223-249.

Schwarzenbach, Alexis. 1999. Portraits of the Nation: Stamps, Coins, and Banknotes in Belgium and Switzerland, 1880-1945. Vol. III/847. European University Studies. Bern-New York: Peter Lang.

Scott Publishing. 2007. Scott 2008 Standard Postage Stamp Catalogue, editado por James E. Kloetzel. Sidney: Scott Publishing.

Scott, David. 1995. European Stamp Design: A Semiotic Approach to Designing Messages. London: Academy Editions.

Shanahan, Suzanne. 2003. "Currency and Community: European Identity and the Euro". En Figures d'Europe: Images and Myths of Europe, editado por Luisa Passerini, 159-179. Bruxelles: PIE-Peter Lang.

Siebertz, Roman. 2005. Die Briefmarken Irans als Mittel derpolitischen Bildpropaganda. Wien: Österreichische Akademie der Wissenschaften.

Spillman, Lyn. 1997. Nation and Commemoration: Creating National Identities in the United States and Australia. Cambridge \& New York: Cambridge University Press.

Stoetzer, Carlos. 1953. Postage Stamps as Propaganda. Washington, DC: Public Affairs Press.

Taylor, Charles. 2004. Modern Social Imaginaries, Public Planet Books. Durham: Duke University Press.

Tenorio-Trillo, Mauricio. 1996. Artilugio de la nación moderna: México en las exposiciones universales, 1880-1930. México: Fondo de Cultura Económica.

Unwin, T.y V. Hewitt. 2001. "Banknotes and National Identity in Central and Eastern Europe". Political Geography 20, n. ${ }^{\circ}$ 8: 1005-1028. 
VV. AA. 1986. El nacionalismo y el arte mexicano, $9^{\circ}$ coloquio de historia del arte. Mexico: UNAM.

Vasconcelos, José. 1997 [1925]. The Cosmic Race / La raza cósmica. Traducido por Didier Tisdel Jaén Baltimore \& London: Johns Hopkins University Press.

Vaughan, Mary K. y Stephen Lewis, editores. 2006. The Eagle and the Virgin: Nation and Cultural Revolution in Mexico, 1920-1940. Durham \& Chesham: Duke University Press.

Veselkova, Marcela y Julius Horvath. 2011. "National Identity and Money: Czech and Slovak Lands 1918-2008”. Nationalities Papers 39, n. ${ }^{\circ}$ 2: 237-255.

Wallach, Yair. 2011. "Creating a Country through Currency and Stamps: State Symbols and Nationbuilding in British-ruled Palestine". Nations and Nationalism 17, n. ${ }^{\circ}$ 1: 129-147.

Zárate Toscano, Verónica. 2003. "El papel de la escultura conmemorativa en el proceso de construcción nacional y su reflejo en la ciudad de México en el siglo XIX”. Historia Mexicana 53, n. ${ }^{\circ}$ 2: 417-446. 